\title{
PROGNOSTIC VALUE OF A 90kD SUBUNIT CONTAINING GLYCOPROTEIN TUMOR-ASSOCIATED ANTIGEN SPECIFIC IMMUNE COMPLEXES IN LUNG CANCER PATIENTS
}

\author{
RISHAB K. GUPTA AND DONALD L. MORTON \\ John Wayne Cancer Institute at Saint John's Hospital and Health Center, 2200 Santa Monica Boulevard, \\ Santa Monica, California 90404, U.S.A.
}

\section{SUMMARY}

An ELISA to detect a glycoprotein TAA-specific immune complexe (IC) has been developed utilizing a murine monoclonal antibody, AD $1-40 \mathrm{~F} 4$, that recognizes a $90 \mathrm{kD}$ subunit of the antigen. In this study we determined the applicability of the assay to assess the presence of the glycoprotein TAA-IC in lung cancer patients. The incidence of glycoprotein TAA-IC was 63\% (33/89), significantly higher $(p<0.05)$ than normal controls $(3.2 \% ; 8 / 250)$. Comparative analyses of preand post-operative sera of non-small cell lung cancer patients revealed that in $30 \%$ (20/66) of patients, the ELISA value for the marker did not become negative, i.e., decrease below the cut-off level $\left(0.410 \mathrm{OD}_{\mathrm{nm}}\right)$ after surgical resection of the tumor. It is postulated that these patients either had extensive disease or microscopic metastases that were not resectable.

Evaluation of post-operative glycoprotein TAA-IC results in relation to disease recurrence revealed a significant association between the presence of the antigen in serum and disease recurrence. There did not appear to be any association between the glycoprotein TAA-IC and the other conventional marker, CEA; however, using more than one marker increases the incidence of detection of the disease.

KEY WORDS Lung cancer 90kD Glycoprotein TAA Immune complexes

Murine monoclonal antibodies Tumor marker CEA

\section{INTRODUCTION}

Carcinoma of the lung causes a large number of deaths in the general population and surpasses all other disseminated malignancies (Boring et al., 1994). The overall 5 year survival for lung cancer patients is usually less than 20 percent. The very low survival rate may be due in part to the fact that by the time the disease is diagnosed, it has already metastasized. As a result, only a few lung cancer patients are suitable candidates for potentially curative treatment. Thus, there is a pressing need to develop improved diagnostic and prognostic tumor marker assays that can detect the disease as early as possible.

To date there is no single ideal tumor marker available that can be used for human lung cancer. According to the literature, carcinoembryonic antigen (CEA), the "classic" tumor marker for lung cancer, is of marginal value in the diagnosis, prognosis, and early

Correspondence to: Rishab K. Gupta, Ph.D., John Wayne Cancer Institute, 2200 Santa Monica Blvd., Santa Monica, CA 90404, U.S.A. Telephone: (310) 449-5265; Telefax: (310) 449-5259. 
detection of the disease (DeJong-Bakker et al., 1981). Tissue polypeptide antigen (TPA) has also been a commonly studied tumor marker with very limited success (Skyrten et al. 1981); it is not specific for lung cancer.

The search for tumor antigens specific for lung cancer has accelerated considerably since the 1980s, and the introduction of murine monoclonal antibody technology facilitated this search. With the use of a variety of different immunogens including intact lung cancer cells, a number of lung cancer-associated antigens have been identified and applied for assessment of their clinical usefulness, e.g., neuron-specific enolase (Cooper and Splinter, 1987), chromogranin A (Sobol et al., 1986), CA-50 (Holmgren et al., 1984; Brezicka et al., 1992), tissue polypeptide antigen (TPA) (Luthgens and Schlegel, 1987; Buccheri and Ferrigno, 1992), etc. Despite this progress within the past few years that defined the role of tumor markers in treatment monitoring, staging, prognosis and diagnosis of lung cancer, no single marker has yet been identified to have a major clinical importance (Bergman et al., 1993; Hansen and Hansen, 1989; Lombardi et al., 1990; Stahel, 1992; Souhami et al., 1991; Stieber et al., 1993). Furthermore, none of these markers has been shown to be immunogenic in lung cancer patients.

In addition to the murine monoclonal antibody-defined tumor markers, certain tumorassociated antigens (TAA) expressed by human neoplasms, including lung carcinoma, have resulted in the formation of autoantibodies that persist in circulation (Salinas et al., 1985). These autoantibodies specifically react with immunogenic TAA when it appears in the circulation of cancer patients. In fact, several reports have suggested that an assessment of circulating immune complex (IC) levels was useful for monitoring the clinical course of cancer patients (Eiras et al., 1980; Gropp et al., 1980; Bukh et al., 1989). A correlation was observed between IC levels and the clinical course of the disease. Elevation of IC and CEA in lung cancer patients beyond the immediate post-operative period was predictive of a significantly shorter median survival time than normal levels (Dent et al., 1980). Despite positive correlations, application of the IC detection assays for practical purposes has met with limited success. This is because the majority of the IC detection assays that have been used were not antigen-specific, and false-positive results could have arisen due to apparent and unapparent infections (Herberman et al., 1981). Thus, it is important to determine the origin of the antigen portion of the immune complexes.

We previously described a glycoprotein (TAA) using allogeneic antibodies (Rote et $a l ., 1980$ ). This antigen is expressed by various histologic types of human solid tumors including a lung carcinoma cell line, P3 (Gupta et al., 1983; Hatzitheofilou et al., 1987). A murine monoclonal antibody (MuMoAb), AD1-40F4, of IgM isotype which recognized the $90 \mathrm{kD}$ subunit of the antigen was developed using the purified TAA (Euhus et al., 1989a, 1990a). The epitope on the $90 \mathrm{kD}$ subunit recognized by the MuMoAb is different from those epitopes recognized by allogeneic antibodies (Euhus et al.,1990b). With the availability of the glycoprotein TAA, which is immunogenic in a cancer host, and with the availability of MuMoAb directed to this antigen, we developed a TAAspecific IC detection assay (Gupta and Morton, 1992). This assay circumvents the problems associated with antigen non-specific IC detection assays and eliminates the need to characterize the antigen portion of the IC.

This assay utilizes the immobilized MuMoAb (AD1-40F4) as a catcher of the glycoprotein TAA via the specific epitope on the $90 \mathrm{kD}$ subunit, with subsequent detection of the autologous human antibody by ELISA. Present investigations were undertaken to assess the value of the glycoprotein TAA-specific IC assay as a possible 
tumor marker for patients with lung carcinoma, and to compare the results of this assay with those of CEA.

\section{MATERIALS AND METHODS}

\section{Patient Population}

This study included 89 patients who had histopathologically proven non-small cell lung cancer. According to the histopathologic diagnosis, 32 patients had squamous cell, 40 patients had adenocarcinoma, and 17 patients had large cell carcinoma. Follow-up period of the patients ranged from 2 to 156 months with a median of 15 months, and each follow-up visit consisted of clinical and radiologic examinations. Serum samples were obtained pre-operatively and post-operatively at each visit, and stored at $-35^{\circ} \mathrm{C}$. There were $56 \%(50 / 89)$ males. The median age was 59 years with a range of 31 to 74 years.

\section{Tumor Marker Assays}

Glycoprotein TAA with $90 \mathrm{kD}$ subunit: We developed a tumor antigen specific IC detection assay that utilizes immobilized MuMoAb directed to the $90 \mathrm{kD}$ subunit of the glycoprotein TAA. This antigen is expressed by $82 \%(18 / 22)$ carcinomas. Details of the assay have been described elsewhere (Gupta and Morton, 1992). In brief, $100 \mathrm{ul} \mathrm{AD1-}$ $40 \mathrm{~F} 4$ ascites fluid diluted to a protein concentration of $100 \mathrm{ug} / \mathrm{ml}$ was dispensed into each of the appropriate wells of glutaraldehyde-activated microtiter plates (Dynatech Laboratories, Chantilly, VA). The plates were incubated at $4{ }^{\circ} \mathrm{C}$ for $16 \mathrm{hrs}$ and then washed with PBS supplemented with $0.5 \%$ Triton X-100 (PBS-TX). The washed plates were blocked with $100 \mathrm{ul}$ per well of $1 \%$ bovine serum albumin (BSA) in PBS-TX at $23^{\circ} \mathrm{C}$ for $1.0 \mathrm{hr}$. Test serum samples were diluted 1:60 with PBS-TX supplemented with $1 \%$ BSA, $0.5 \%$ normal mouse serum and $0.01 \mathrm{M}$ ethylenediaminetetraacetic acid (EDTA). One hundred microliters of the diluted sample was dispensed into duplicate wells of the activated plates and incubated at $37^{\circ} \mathrm{C}$ for $45 \mathrm{~min}$. At the end of incubation the wells were washed with PBS-TX. One hundred microliters of alkaline phosphatase conjugated to Fab fragment of goat anti-human IgG (Sigma Chemical Company, Saint Louis, MO) at 1:500 dilution in $1 \%$ BSA and $0.5 \%$ mouse serum supplemented PBS-TX was added to each test and control wells of the plate. The plates were incubated at $37^{\circ} \mathrm{C}$ for $45 \mathrm{~min}$. and washed with PBS-TX. Each well of the plate then received 200 ul of p-nitrophenyl phosphate $(1.0 \mathrm{mg} / \mathrm{ml})$ in $10 \%$ diethanolamine buffer as the substrate and the plates were incubated in the dark for $1 \mathrm{hr}$ at $23^{\circ} \mathrm{C}$. The absorbance was read at $405 \mathrm{~nm}$. Each sample was tested in duplicate with positive and negative controls and blanked individually in the same microtiter plate. Each test plate also included controls for non-specific protein binding and binding of conjugate to the immobilized murine monoclonal (capturing) antibody. The net optical densities of the control samples were used to generate a correction factor to normalize the net optical density of the test samples analyzed on that particular test plate. If the correction factor for a test plate fell outside the range from 0.8 to 1.2 , the assay was considered invalid. The upper limit of normal for the glycoprotein TAA marker was set at 0.41 (mean +3 SD ELISA values of 59 normal sera). Inter- and intra-assay variability of the assay, as measured in terms of coefficient of variation, ranged from 10 to $18 \%$ (Gupta and Morton, 1992).

Carcinoembryonic antigen: CEA measurements on 41 pre-operative serum samples of lung cancer patients and 119 serum samples from self-proclaimed normal volunteers were performed by Dianon Systems, Inc., Stratford, Connecticut, using Abbott CEA- 
EIA procedures that followed manufacturer's instructions. A value of above $5 \mathrm{ng} \mathrm{CEA} /$ $\mathrm{ml}$ was considered positive.

\section{Statistical Procedures}

Chi-square or Fisher's exact test as implemented by the Instat Biostatistics program from the GraphPad Software, Inc., San Diego, Ca., was used to compare the results between CEA and the glycoprotein TAA. Mann-Whitney test was used to determine the statistically significant differences among the glycoprotein TAA ELISA values of normal and lung cancer groups. Differences between recurrence and no evidence of disease in follow-up of lung cancer patients were determined by the Mantel-Cox log rank test using BMDP statistical software developed by Health Science Computing Facility, University of California at Los Angeles. All tests were two-tailed and a $p$ value of less than 0.05 was considered statistically significant.

\section{RESULTS}

\section{Incidence of $90 \mathrm{kD}$ Subunit Containing Glycoprotein TAA-IC in Lung Cancer}

Figure 1 compares the distribution of glycoprotein TAA-IC ELISA values in sera from 89 lung cancer patients and from 250 normal individuals. The normal group comprised 117 males and 133 females who ranged in age from 10 to 74 years and their results were reported earlier (Gupta and Morton, 1992). Both incidence (63\%) and ELISA values $(0.574 \pm 0.29$; mean $\pm \mathrm{SD})$ were significantly higher in the lung cancer group than in the normal group ( $p<0.05$ by Mann-Whitney test). The incidence of the glycoprotein TAAIC was about the same in all histologic types of non-small cell lung cancer. The serum samples in the lung cancer group were obtained pre-operatively.

\section{Results of Pre-and Post-operative Sera of Lung Cancer Patients}

Comparative analysis of pre- and post-operative serum samples from the 89 lung cancer patients for the glycoprotein TAA-IC revealed that the ELISA values of 8 to 16 weeks post-operative serum samples of several patients decreased significantly; whereas, these values in some patients did not change appreciably or did not decrease to the negative level. As illustrated in Figure 2, alignment of pre-operative serum data values in an ascending order and on the basis of the post-operative serum remaining positive revealed that the patients could be grouped into three categories. Group I included those patients that were negative for the presence of glycoprotein TAA-IC both before and after surgical resection of their tumor. It is possible that the tumors of these patients did not express the glycoprotein TAA or an antigen excess rendering the antigenspecific immune complexes undetectable by the present format of the assay. The second group (group II) included those patients who were positive pre-operatively but became negative after surgical resection of tumor. Group III included those patients who remained positive for the glycoprotein TAA-IC post-operatively. In this group of patients, apparently the disease was extensive and perhaps these patients had micrometastases.

\section{Analysis of Sequential Serum Samples and Correlation with Recurrence}

Sequential serum samples of lung cancer patients were analyzed for the presence of the glycoprotein TAA-IC. The results were correlated with clinical status of the disease. 


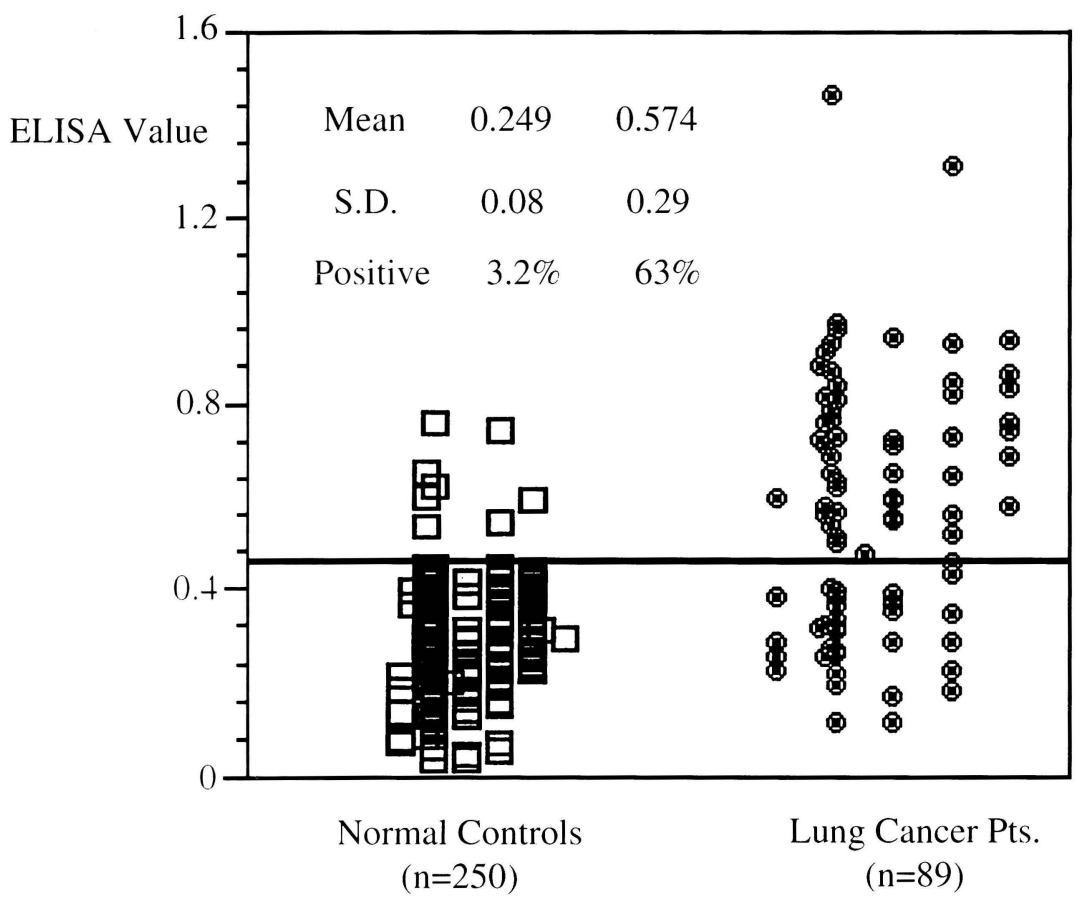

Figure 1. Incidence of glycoprotein TAA-IC in sera of self-proclaimed normal and non-small cell lung cancer patients. Sera from lung cancer patients were obtained before surgery. Cut-off level 0.410 OD at $405_{\mathrm{nm}}$ (mean plus 3 SD of normal, in represented by the solid horizontal line.

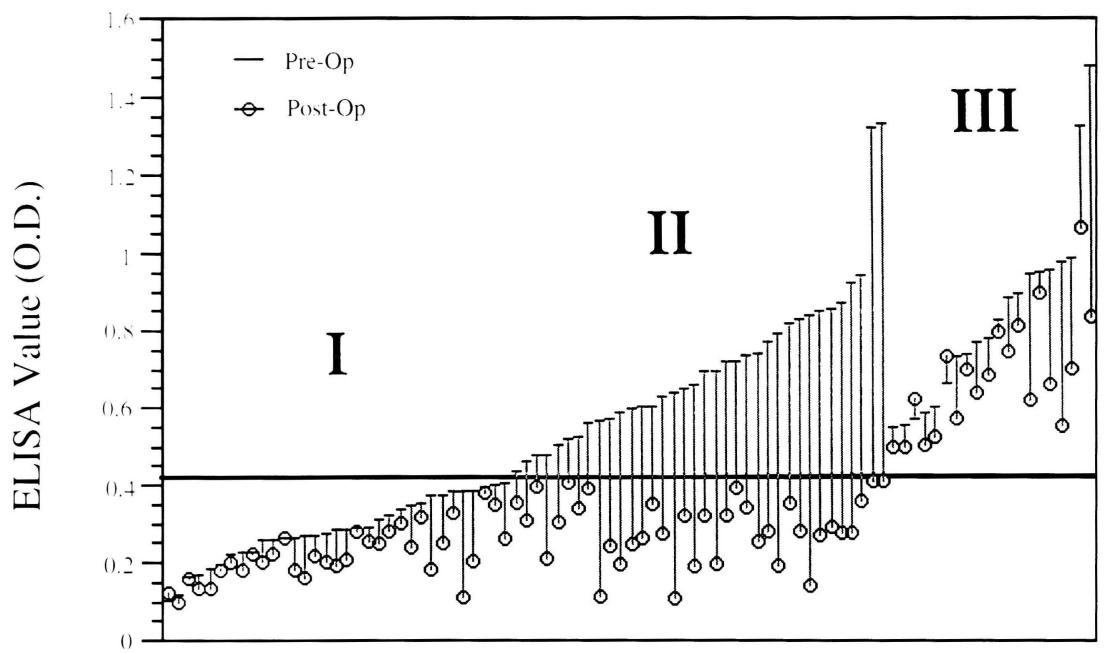

Figure 2. ELISA values for glycoprotein TAA-IC in pre- and post-operative serum samples of 89 non-small cell lung carcinoma patients. A dash (-) denotes the ELISA value of pre-operative sample. An open circle (0) denotes the ELISA value of post-operative serum sample. The vertical dotted line between (-) and $(0)$ denotes the two pre- and post-operative serum values of the same patient. 


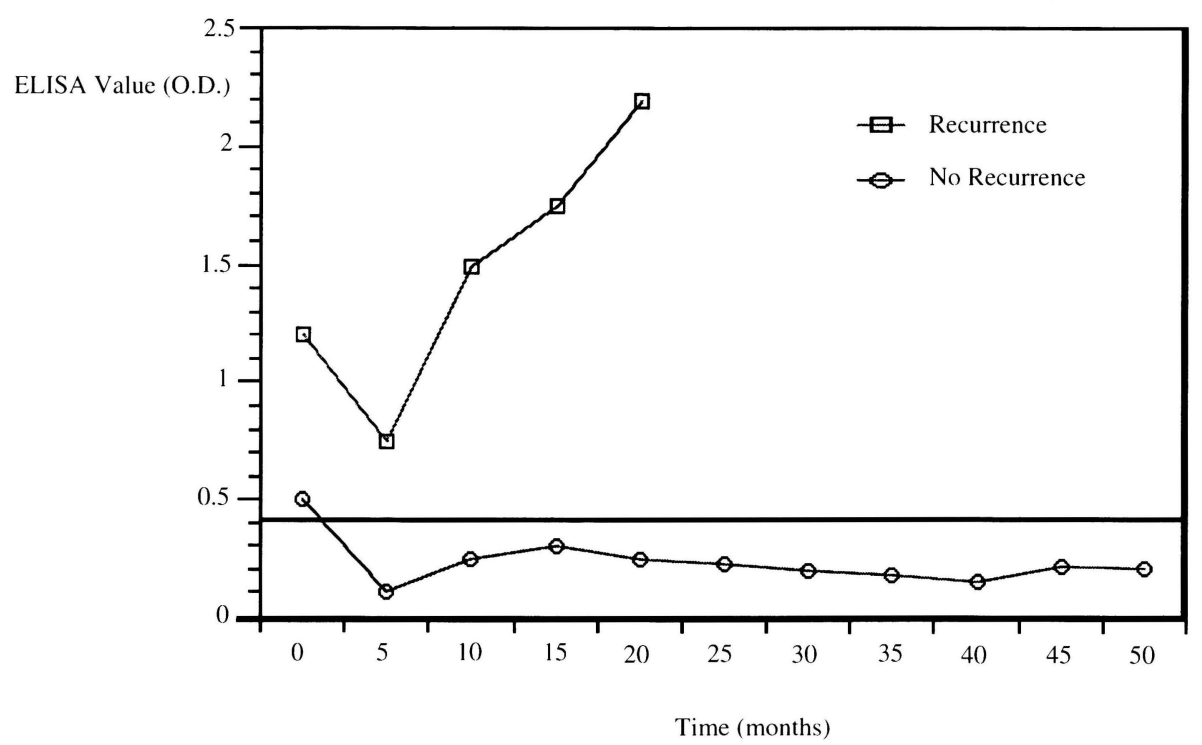

Figure 3. Glycoprotein TAA-IC values in sequential serum samples of two representative lung cancer patients. Horizontal solid line denotes cut-off level of positive (above) and negative (below) values.

Figure 3 illustrates results of sequential serum samples of two representative patients. The glycoprotein TAA-IC values were consistently elevated post-operatively in the patient who developed recurrent disease. In contrast, these values remained low for most of the post-operative sequential serum samples of the patient who remained disease free during the follow up period of 50 months.

A patient was considered post-operatively positive for the glycoprotein TAA-IC when two or more consecutive serum samples had an ELISA value of greater than $0.41 \mathrm{OD}_{405}$. The negative and positive patients were then evaluated in relation to disease recurrence by Chi-square. As shown in Table 1, a significant association existed between the presence of glycoprotein TAA-IC in serum and disease recurrence $(p<0.05)$. Sixty-six percent of patients positive for the glycoprotein TAA-IC developed recurrent disease and $75 \%$ patients negative for the marker remained disease free for the follow-up period.

Subsequent statistical analysis of the data by log rank test revealed that the rate of recurrence among post-operatively glycoprotein TAA-IC positive patients was about $80 \%$ as opposed to $40 \%$ in the negative group; this difference was statistically significant.

\section{Association Between Glycoprotein TAA-IC and CEA}

CEA has been considered a useful marker in the prognosis and monitoring of lung cancer patients. We compared the glycoprotein TAA-IC using selected serum samples with this classical tumor marker (CEA), which is not immunogenic in cancer patients.

Of the 41 pre-operative serum samples from lung cancer patients, 27 (66\%) were positive for the glycoprotein TAA, and $18(44 \%)$ were positive for CEA. The incidence of positive CEA in normal sera was $4.2 \%(5 / 119)$; whereas, the incidence of positive glycoprotein TAA in this group of normal sera was $3.4 \%$ (4/119). None of the normal sera positive for CEA was positive for the glycoprotein TAA and vice versa. As shown in Table 2, analyses by Fisher's exact test revealed that there was no significant relationship 
Table 1. Relationship between post-operative presence of glycoprotein TAA-IC and recurrent disease in lung cancer patients.

\begin{tabular}{lccc}
\hline & \multicolumn{2}{l}{ Disease recurrence } & \\
\cline { 2 - 3 } Glycoprotein TAA-IC result & Yes & No & Total \\
\hline Positive* & 35 & 9 & 44 \\
Negative & 18 & 27 & 45 \\
Total & 53 & 36 & 89 \\
\hline
\end{tabular}

*A patient was considered glycoprotein TAA-IC positive when two consecutive serum samples had the ELISA value of greater than 0.41 at $405 \mathrm{~nm}$.

$p<0.05$ by chi-square.

Table 2. Association between serum glycoprotein TAA-IC and CEA

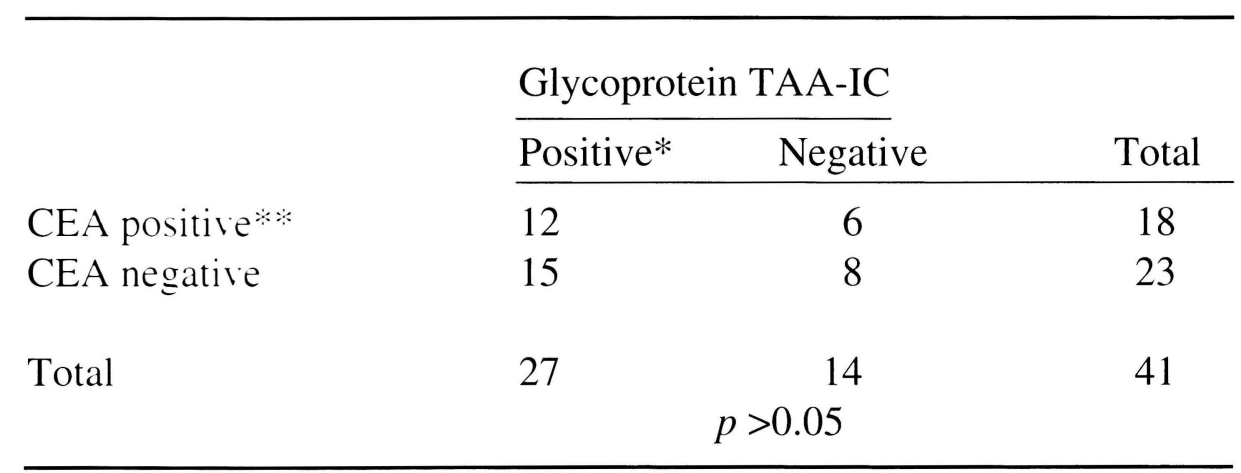

*An ELISA value of greater than $0.41 \mathrm{OD}$ at $405 \mathrm{~nm}$ was considered positive.

** A value of greater than $5 \mathrm{ng} \mathrm{CEA} / \mathrm{ml}$ was considered positive.

Table 3. Incidence of positivity for glycoprotein TAA-IC and CEA or their combination in sera from lung cancer patients

Marker

Incidence $(n=41)$

(Alone or in combination)

CEA only

Number positive Percent positive

TAA only

18

44

TAA and/or CEA 
between the glycoprotein TAA and CEA levels $(p>0.05)$. However, when either of the two or both positive markers are taken into consideration, the incidence of positivity in lung cancer patients increased from $44 \%$ to $80 \%$ (Table 3 ). Thus, they appear to independently correlate with disease outcome.

\section{DISCUSSION}

There are a number of biochemical and immunological markers available for diagnosis, prognosis and monitoring of lung cancer (Cooper, 1987). However, the majority of these markers are neither sensitive nor specific enough to warrant their widespread use in the management of patients with this disease (Kakari et al., 1991). In general, the greater the tumor burden at diagnosis, the more elevated the serum concentration of the marker; post-treatment marker levels vary according to the changes in disease status (Buccheri and Ferrigno, 1992). Most of the tumor markers defined and applied for lung cancer are either biochemical, hormonal or molecules defined by murine monoclonal antibodies. None of these has been shown to be immunogenic in the patients.

In this study we have used a well-developed tumor-associated antigen specific immune complex detection assay to determine the presence of a glycoprotein TAA which is expressed by $82 \%$ of carcinomas. This assay utilizes a murine monoclonal antibody that specifically recognizes an epitope on the $90 \mathrm{kD}$ subunit of the antigenic molecule, and this epitope is different from the ones that are recognized by patients' antibodies. IgM murine monoclonal antibodies are difficult to work with due to their instability and sticky nature; however, we have successfully utilized them to generate a solid support leaving the antigen binding site accessible to interact with the specific epitope. We feel that the success of the $90 \mathrm{kD}$ subunit containing glycoprotein TAA-IC assay for the detection of lung cancer in early stage is because immunogenic tumor antigens are shed into the circulation by growing tumor cells in small enough quantities to be neutralized by humoral antibodies (Euhus et al., 1989b). Thus, the results of any sensitive methods applied to detect free antigens in serum or plasma are generally negative. However, detection of human antibody (immunoglobulin) molecules via the antigen captured by the immobilized MuMoAb gives a amplification effect. This is because the unreduced antigen is a complex of at least four different subunits (Euhus et al., 1990b), each of which is immunogenic in the cancer host, and can bare multiple in vivo reacted immunoglobulin molecules. Furthermore, glycoprotein TAA being immunogenic in cancer patients should circulate in bloodstream in the form of soluble immune complexes, particularly at a time when the source of the tumor is present only in small amounts - a situation that represents antibody excess.

Despite the fact that our earlier studies with melanoma indicated that the assay was not $100 \%$ accurate in detecting the presence of the disease, it had sufficient merit to discriminate between normal and abnormal sera. We have now extended that approach to lung cancer. Our results show that the incidence of the glycoprotein TAA-IC is significantly higher in patients with non-small cell carcinoma of the lung than normal controls. This incidence was not affected by the age of lung cancer patients or the histopathology of the non-small cell lung cancer. Comparative analysis of pre-and postoperative sera of the 89 lung cancer patients revealed that the patients could be grouped into three categories. The first group included those patients that were negative for the presence of glycoprotein TAA specific IC, both before and after surgical resection of the 
disease. It is possible that tumor of patients in this group did not express the glycoprotein TAA. This possibility needs to be confirmed by analyzing tumor tissue and serum from the same patients for the presence of the glycoprotein TAA. The second group included those patients that were positive pre-operatively but became negative after surgical resection of the disease. Clearly, patients in this group benefited from surgery in that either they were rendered disease free or their tumor burden was reduced to below the detection limit of the assay. The third group included those patients that remained positive for the TAA-specific IC post-operatively. In this group of patients, apparently the disease was extensive or these patients had micrometastases.

It was evident from analysis of sequential serum samples that the glycoprotein TAAIC values were consistently high in the patient who developed recurrent disease. In contrast, these values remained low for most of the sequential serum samples of the patient who remained disease free during the follow up period. Even though we did not reach $90 \%$ or greater accuracy in predicting the outcome of lung cancer patients, our results are highly encouraging in identifying patients who are at high risk of developing recurrent disease due to micrometastases. We are now working towards improving the assay sensitivity and identifying additional immunogenic tumor antigens associated with lung cancer for their application to reduce false positives.

\section{ACKNOWLEDGEMENTS}

These investigations were supported by the grant RT77 awarded by the Tobacco Related Disease Research Program of the State of California, by the Department of Human Health Services grants CA 29605, CA 30019 and CA 12582, and by the John Wayne Cancer Institute Auxiliary. We gratefully acknowledge the expert technical assistance of Mr. Reynold Yee, Mr. Zacarias Leopoldo, and Mr. Thomas Sumobay.

\section{REFERENCES}

Bergman, B., Brezicka, F.-T., Engstrom, C.-P., Larsson, L. (1993). Clinical usefulness of serum assays of neuron-specific enolase, carcinoembryonic antigen and CA-50 antigen in the diagnosis of lung cancer. Eur. J. Cancer, 29A, 198-202.

Boring, C.C., Squires, T.S., Tong., T., Montgomery, B.A. (1994). Cancer statistics, 1994. CA Cancer J. Clin., 44, 7-26.

Brezicka, F.-T., Olling S., Bergman, B., Berggren, H., Engstrom, C.-P., Hammerstrom, S., Holmgren, J., Larsson, S., Lindholm, L. (1992). Coexpression of ganglioside antigen Fuc-GM1, neural-cell adhesion molecule, carcinoembryonic antigen and carbohydrate tumor-associated antigen CA-50 in lung cancer. Tumor Biol., 13, 308-315.

Buccheri, G., Ferrigno, D. (1992). Prognostic value of the tissue polypeptide antigen in lung cancer. Chest, 101, 1287-1292.

Bukh, A., Kinose, H.H., Aguado, M.T., Linnet, L., Miller, N.P. (1989). A comparative study of the level of circulating immune complexes in pulmonary blood draining the tumor area and peripheral venous blood. Int. J. Cancer, 43, 837-840.

Cooper, E.H., Splinter, T.A.W. (1987). Neuron-specific enolase (NSE): a useful marker in small cell lung cancer. Lung Cancer, 3, 61-66.

De Jong-Bakker, M., Hart, A.M. Persijju, J.P., Cleton, F.J. (1981). Prognostic significance of CEA in lung cancer: A statistical study. Eur. J. Cancer, 17, 1307-1313. 
Dent, P.B., Louis, J.A., McCulloch, P.B., Dunnett, C.W., Cerottini, J. (1980). Correlation of elevated $\mathrm{Clq}$ binding activity and carcinoembryonic antigen levels with clinical features and prognosis in bronchogenic carcinoma. Cancer, 45, 130-136.

Eiras, A.S., Robins, R.A., Baldwin, R.W., Byers, V.S. (1980). Circulating immune complexes in patients with bone tumors. Int. J. Cancer, 25, 735-739.

Euhus, D.M., Gupta, R.K., Morton, D.L. (1989a). Detection of a tumor associated glycoprotein antigen in serum and urine of melanoma patients by murine monoclonal antibody (AD1-40F4) in enzyme immunoassay. J. Clin. Lab. Analysis, 3, 184-190.

Euhus, E.M., Gupta, R.K., Morton, D.L. (1989b). Induction of antibodies to a tumor associated antigen by immunization with a whole melanoma cell vaccine. Cancer Immunol. Immunother., 26, 247-254.

Euhus, D.M., Gupta, R.K., Morton, D.L. (1990a). Characterization of a 90-100 kDa tumorassociated antigen in the sera of melanoma patients. Int. J. Cancer, 45, 1065-1070.

Euhus, D.M., Gupta, R.K., Morton, D.L. (1990b). Association between allo-immunoreactive and xeno-immunoreactive subunits of a glycoprotein tumor-associated antigen. Cancer Immunol. Immunother., 32, 214-220.

Gropp, G., Haveman, K., Scherfe, T., Ax, W. (1980). Incidence of circulating immune complexes in patients with lung cancer and their effect on antibody-dependent cytotoxicity. Oncology, 37, $71-76$

Gupta, R.K., Huth, J.F. Korn, E.L., Morton, D.L. (1983). Prognostic significance of urinary antigen analysis by enzyme-linked immunosorbent assay in melanoma patients. Diag. Immunolol., 1, 303-309.

Gupta, R.K., Morton, D.L. (1992). Monoclonal antibody based ELISA to detect glycoprotein tumor-associated antigen specific immune complexes in cancer patients. J. Clin. Lab. Analysis, 6, 329-336.

Hansen, M., Hansen, H.H. (1989). Tumour markers in the clinical management of patients with small cell lung cancer. Eur. Resp. J., 2, 700-701.

Hatzitheofilou, C., Kern, D.H., Gupta, R.K., Campbell, M.A., Morton, D.L. (1987). A radioimmunometric assay for the detection and characterization of lung cancer-associated antibodies in sera of lung cancer patients. J. Surg. Res., 42, 85-91.

Herberman, R.B., Border, M. Lambert, P.H., et al. (1981). A report on international comparative evaluation of possible value of assays for immune complexes for diseases of human breast cancer. Int. J. Cancer, 27, 569-576.

Holmgren, J. Lindholm, L., Persson, B., Lagergard, T., Nilsson, O., Svennerholm, L., Rudenstam, C.-M., Unsgaard, B., Yngvason, F., Pettersson, S., Killander, A.F. (1984). Detection by monoclonal antibody of carbohydrate antigen CA-50 in serum of patients with carcinoma. $B r$. Med. J., 288, 1479-1482.

Kakari, S. Stringou, E., Toumbis, M. Ferderigos, A.S., Poulaki, E., Chondros, K., Dema, A., Kotsovoulou, V., Pavlidis, N. (1991). Five tumor markers in lung cancer: Significance of total and lipid-bound sialic acid. Anticancer Res., 11, 2107-2110.

Lombardi, C. Tassi, G.F., Pizzocolo, G., Donato, F. (1990). Clinical significance of a multiple biomarker assay in patients with lung cancer. A study with logistic regression analysis. Chest, 97, 639-644.

Luthgens, M., Schlegel, G. (1987). The clinical use of tissue polypeptide antigen (TPA): A review. J. Tumor Marker Oncol., 2, 261-271.

Rote, N.S., Gupta, R.K., Morton, D.L. (1980). Determination of incidence and partial characterization of tumor-associated antigens found in the urine of patients bearing solid neoplasms. Int J. Cancer, 26, 203-210.

Salinas, F.A., Wee, K.H., Silver, H.K.B. (1985). Clinical relevance of immune complexes, associated antigen, antibodies in cancer. In: Salinas, F.A., Hanna, M.A. (Eds.). Immune Complexes and Human Cancer, Plenum Press, New York, pp. 55-109. 
Skyrten, A.F., Unsgaard, B., Bjorklund, B., Eklund, G. (1981). Serum TPA related to activity in wide spectrum of cancer condition. Tumor Diagnostik, 3, 117-123.

Sobol, R.E., O'Conner, D.T., Addition, J. Suchocki, K., Royston, I., Deftos, L.J. (1986). Elevated serum chromogranin A concentration in small-cell lung carcinoma. Ann. Intern. Med., 105, $698-700$.

Souhami, R.L., Beverley, P.C.L., Bobrow, L.G., Ledermann, J. (1991). Antigens of lung cancer: Results of the Second International Workshop on lung cancer antigen. J. Natl. Cancer Inst., 83, 609-612.

Stahel, R.A. (1992). Morphology, surface antigens, staging, and prognostic factors of small cell lung cancer. Curr. Opin. Oncol., 3, 306-311.

Stieber, P., Bodenmuller, H., Banauch, D., Hasholzner, U., Dessauer, A., Ofenloch-Hahnle, B., Jaworek, D., Fateh-Moghadam, A. (1993). Cytokeratin 19 fragments: a new marker for nonsmall-cell lung cancer. Clin. Biochem., 26, 301-304. 


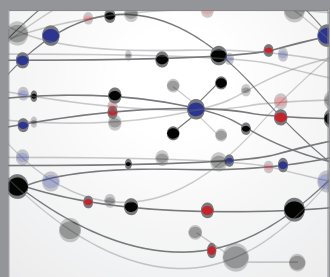

The Scientific World Journal
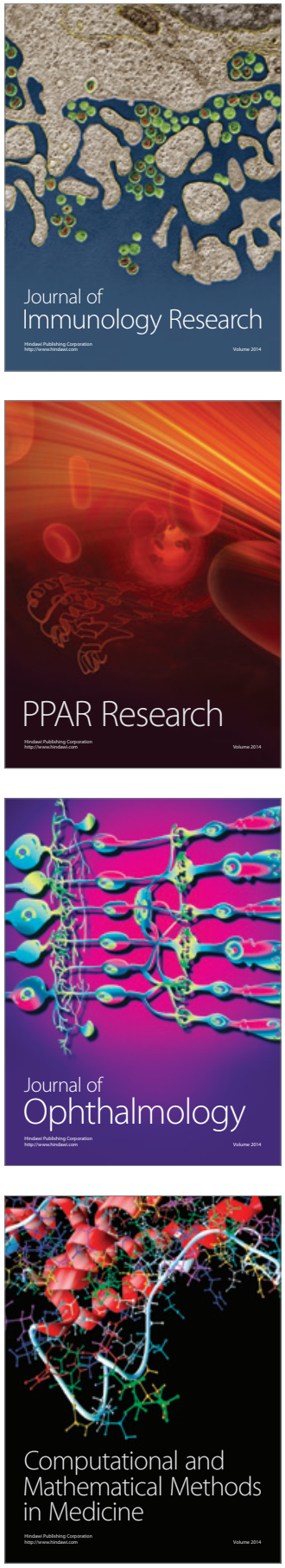

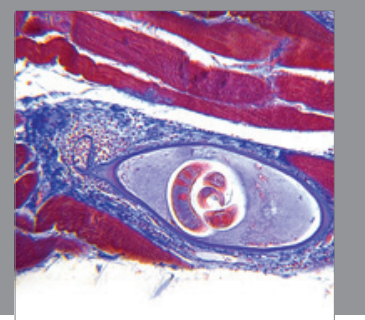

Gastroenterology

Research and Practice
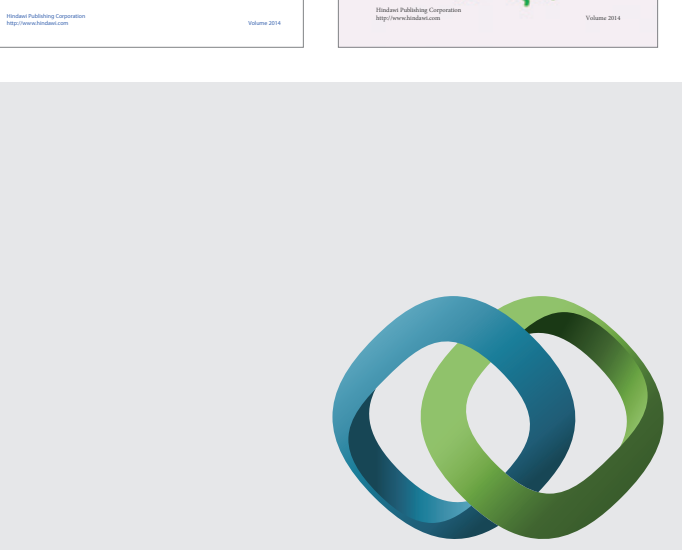

\section{Hindawi}

Submit your manuscripts at

http://www.hindawi.com
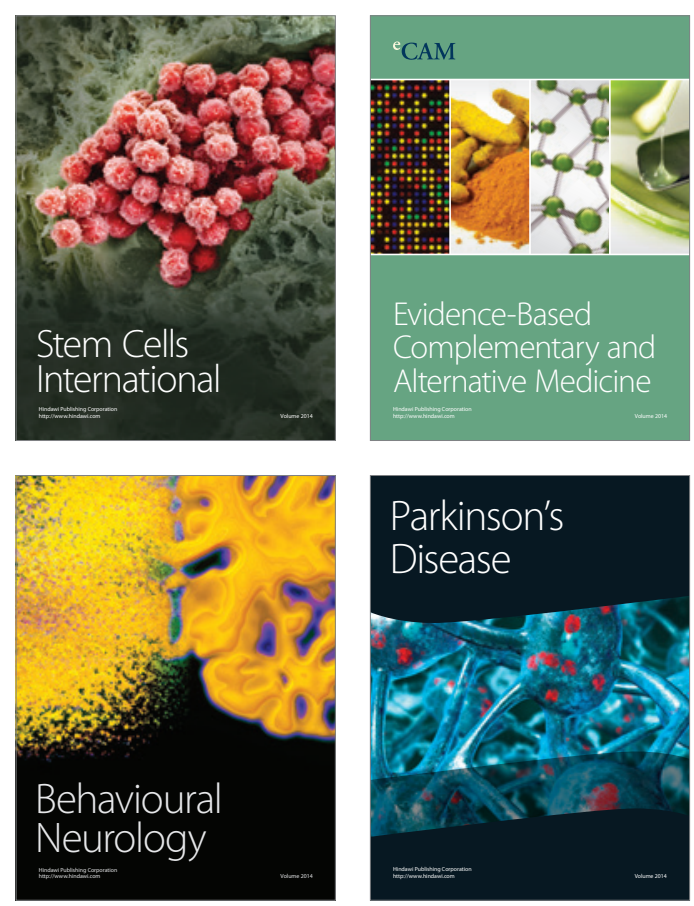

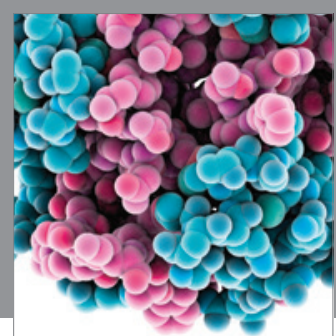

Journal of
Diabetes Research

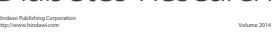

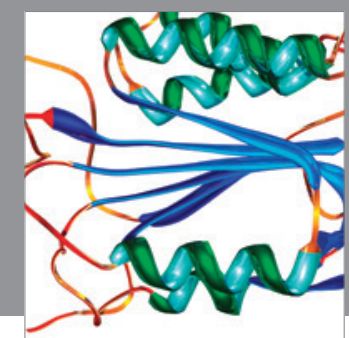

Disease Markers
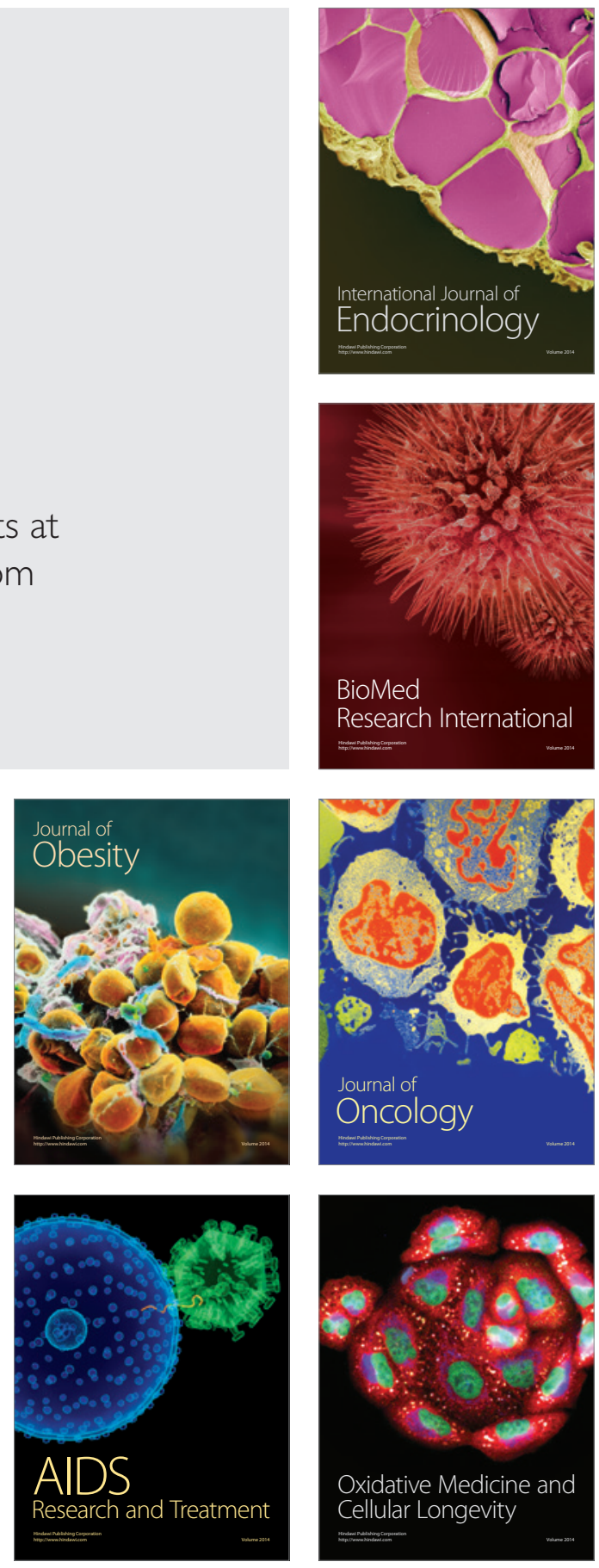